JOURNAL OF THEORETICAL

AND APPLIED MECHANICS

52, 4, pp. 1061-1070, Warsaw 2014

\title{
VISCOPLASTIC PROPERTIES OF AN MR FLUID IN A DAMPER
}

\author{
PAWE€ SKALSKI \\ Institute of Aviation, Centre of New Technologies, Warsaw, Poland; e-mail: pawel.skalski@ilot.edu.pl \\ ROBERT ZALEWSKI \\ Warsaw University of Technology, Institute of Machines Design Fundamentals, Warsaw, Poland \\ e-mail: robertzalewski@wp.pl
}

\begin{abstract}
The aim of this paper is to mathematically describe and analyze the viscoplastic properties of a magnetorehological (MR) fluid. The scope of the discussed research has been limited to the T-MR SiMR 132 DG damper prototype. Laboratory tests have been performed on a specially developed experimental stand with a kinematic excitation rule. On the basis of the experimental data, conventional yield points and maximum shear stresses for the analyzed MR fluid, including variable shear rate, current intensity flowing through a solenoid, liquid temperature and gap height have been analyzed. Basing on the acquired results, the parameters of Bodner-Partom constitutive equations have been estimated. The identified viscoplastic model has been used to carry out simulation tests that enabled verification of the numerical results and real experimental data.
\end{abstract}

Keywords: MR fluid, modeling, Bodner-Partom model, experiments, MR damper

\section{Introduction}

Magnetorheological fluids, beside ferromagnetic and electrorheological fluids, belong to the group of non-Newtonian rheostable fluids which are characterized by the yield point (Carlson and Goncalves, 2008). Magnetic, ferromagnetic and electrorheological fluids are colloidal suspensions of microscopic solids in a liquid carrier, and their main characteristic is rapid grouping of particles into a dense grid under the influence of an external stimulus (Carlson and Weiss, 1994).

Magnetorheological fluids (MRF) are very useful in solving damping problems which are one of the biggest engineering dilemmas of the machines and devices construction and operation. MRFs change their rheological properties under the influence of a magnetic field. These extraordinary properties of MR fluids could not be fully utilized until the age of advanced computer controlling equipment.

MRFs are used in dampers, shock absorbers, clutches and brakes (Goncalves, 2005). MR dampers and shock absorbers are applied e.g. in damping control (Maślanka et al., 2007), in operation of buildings and bridges (Bajkowski et al., 2012) or (Dyke et al., 1996) as well as in damping of high-tension wires $(\mathrm{Wu}, 2006)$. Actually, MR fluids are used in large scale production in the automotive and military industries. It is worth mentioning that MR fluids are also successfully used as a part of various adaptive impact energy absorption systems (Mikułowski and Holnicki-Szulc, 2007) or (Holnicki-Szulc et al., 2009).

In the development and production area of MR fluids, LORD Corporation is a dominating figure on the global market manufacturing the majority of commercialized "smart" fluids and devices. Although plenty of work is currently being led by universities and research centers, there is still a need for a better and more extensive understanding of particular properties of such liquids. Of special interest are investigations of their behavior in various operational conditions, enabling better control of their changeable rheological properties. 
Generally, we can distinguish two main approaches to the modeling of the MR dampers response. In the first one, we are designing the mechanical model of the damper basing on a system of fundamental rheological elements such as springs, dashpots or frictional sliders. In this group of models, the simplest one and at the same time the most popular seems to be the Bingham model (Sapiński and Filuś, 2003). Although it can not reflect the real force-velocity characteristic, it is very popular because of its simplicity and low numerical demand. The second one involves sophisticated mathematical functions describing more accurately the hysteresis loop of the investigated devices. In both considered cases, the models are identified basing on phenomenological observations of the tested MR devices. In such an approach, the model calibration is suitable only for selected constructions, and has to be repeated when another type of MR device is under investigation.

The authors of the paper proposed another approach to the modeling of MR dampers. They attempted to describe the behavior of an MR fluid using viscoplastic constitutive equations which are generally developed for metals. Unlike in the previously mentioned approaches, they do not focus on designing parameters of specific MR dampers but consider only the main part of the system which is the MR fluid. Before taking such a decision, one should ask and answer the following questions: Can constitutive equations be used in the mathematical description of properties of the MR fluid and its nonlinear behavior? Which ones are relevant, and why?

Answering these questions, we should note that in certain operational conditions an MR fluid changes its density, transforming from a liquid to viscoplastic semi-solid, or even solid state. It is one of the most significant features of the investigated MR fluids.

The previously mentioned phenomenon encouraged the authors to describe MR fluids and their viscoplastic properties by using the Bodner-Partom constitutive law.

\section{Research object}

Presented in this paper experimental tests have been carried out for the T-MR SiMR 132 DG damper prototype (Fig. 1), working on the basis of a classical LORD Corporation product - MRF 132 DG. In the investigated device, the gas spring has been neglected. The research program has been carried out using a laboratory stand with the kinematic excitation rule specially developed at the Faculty of Automobile and Construction Machinery Engineering of Warsaw University of Technology (Zalewski et al., 2014).

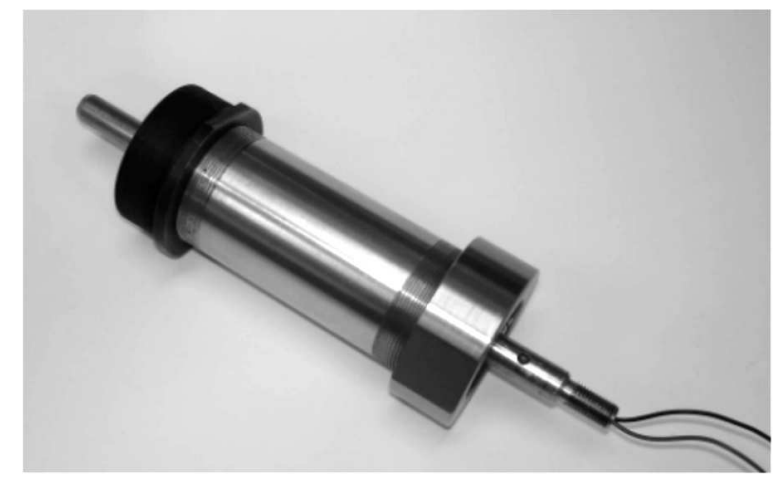

Fig. 1. View of the T-MR SiMR 132 DG damper prototype

The MR fluid examined in this paper is based on hydrocarbons. Typical physical properties of the MRF 132 DG fluid are presented in Table 1, while detailed information is available on the producer's website - www.lord.com. 
Table 1. Fundamental properties of the MRF 132 DG fluid (www.lord.com)

\begin{tabular}{|l|l|}
\hline Properties & MRF $132 \mathrm{DG}$ \\
\hline Viscosity, temperature $40\left[{ }^{\circ} \mathrm{C}\right]$ & $0.092 \pm 0.015$ Pa s \\
\hline Density & $2.98-3.18 \mathrm{~g} / \mathrm{cm}^{3}$ \\
\hline Solids content by weight & $80.98 \%$ \\
\hline Operating temperature & $-40^{\circ} \mathrm{C}-130^{\circ} \mathrm{C}$ \\
\hline Flash point & $>150^{\circ} \mathrm{C}$ \\
\hline Appearance & Dark grey \\
\hline
\end{tabular}

\section{Results of experimental research}

The experimental stand consisted of appropriate force, temperature, speed and displacement sensors. During laboratory tests, the parameters such as force acting on the piston rod, movement of the piston housing, temperature of the outer casing and rotational speed have been recorded.

On the basis of acquired experimental data, detailed analysis of dissipative properties of the investigated prototype has been performed. In this paper, we would like to focus on the impact of chosen operational parameters such as excitation frequency, current intensity, temperature and the gap size.

The final results of our research have been the force-displacement characteristics. As has been previously mentioned, the excitation rule was in a harmonic function form $x(t)=A \sin (\omega t)$ acting directly on the investigated damper piston. The amplitude was assumed to be $A=10 \mathrm{~mm}$. Various rotation speeds of the circular cam were taken into consideration $\omega_{i}=100$, $200,300 \mathrm{rpm}$. The recording time for a single experimental series was $t=5 \mathrm{~s}$, and the sampling frequency $400 \mathrm{~Hz}$. The applied speed resulted in three different values of the piston oscillation frequencies: $f=1.66,3.33,5.00 \mathrm{~Hz}$. Also three currents were taken into account: $I=0.5,1.0$, 2.0 A. Additionally, three different gap sizes (where a flow of MR fluid took place) were examined: $h=5,7,10 \cdot 10^{-4} \mathrm{~m}$. Although the gap size is one of the most important operational parameters of MR devices mainly because of the value of the magnetic flux density across the gap influencing the viscous properties of the fluid, in this paper this problem is omitted. Some information related to this topic can be found in former works by Bajkowski et al. (2008).

The important issue was to determine the impact of oscillation frequency on the experimentally obtained dissipative characteristics of the tested devices. Varying the velocity of the piston movement, changed the speed of the MR fluid flow through the gap, which caused the observed variable damping force. The range of investigated oscillation frequencies was limited by the laboratory stand (the engine power).

Investigating at least three different values of shear rates (oscillation frequencies) is the minimum effort required for the identification process of the Bodner-Partom viscoplastic constitutive model.

Typical dissipative characteristics obtained during laboratory tests are depicted in Fig. 2.

Increasing the current flowing through the solenoid of the MR damper prototype increases the magnetic field acting on the working fluid. According to assumptions, a higher magnetic field transforms the MR fluid from a dense liquid consistency into a gel-like substance. This phenomenon is visible in Fig. 2, better dissipative properties of the MR damper are observed at higher currents. 


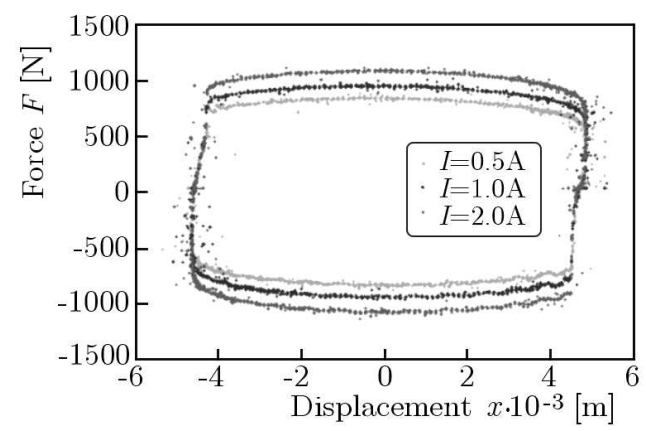

Fig. 2. Damping force characteristics for various currents; temperature $25^{\circ} \mathrm{C}$, frequency $1.66 \mathrm{~Hz}$

\section{Analysis of the MR fluid}

The results of cyclic experimental tests of the MR damper became a basis for the analysis of viscoplastic properties of the MR fluid under the influence of a magnetic field in operational conditions of the damper. To prepare suitable data for conducting the identification process of the Bodner-Partom model, yield point values have been first determined for various shear rates (Kłosowski et al., 2004).

Data depicted in Fig. 3a shows an example characteristic illustrating the full change in force values acting on the piston rod of the tested damper in a rod displacement function. For further identification only the initial part of the force-displacement diagram was taken into consideration (Fig. 3b).
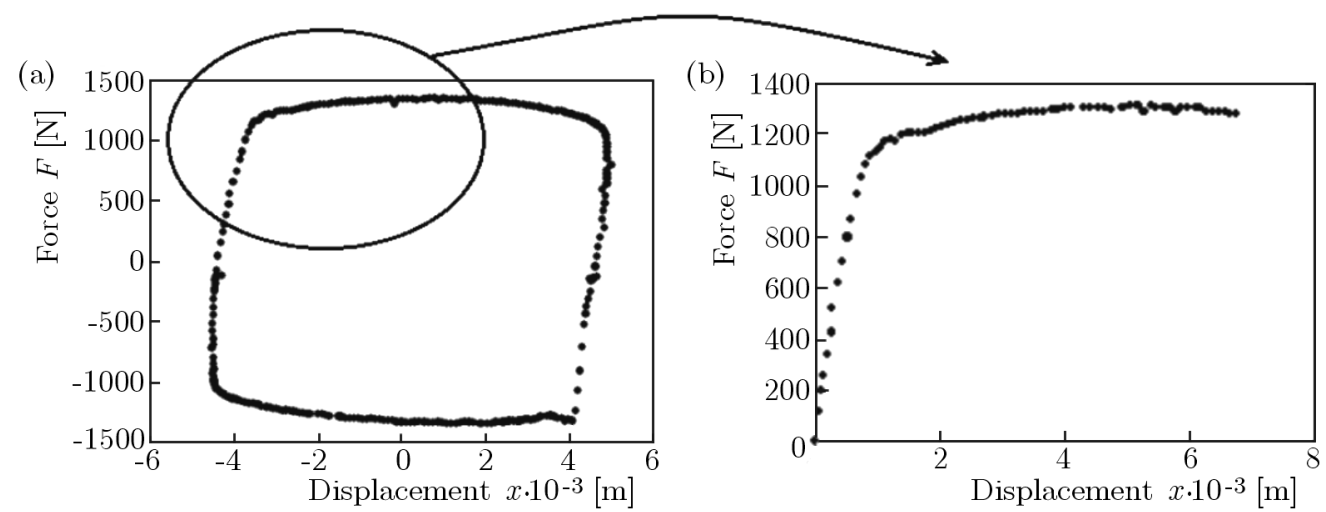

Fig. 3. Damping force in function of the displacement; (a) full cycle, (b) data necessary for the identification process

Prior to the relevant experimental research, the authors estimated the impact of the dry friction force on the acquired results. To evaluate its influence, a series of laboratory tests without the MR fluid were conducted. The experimentally observed friction was less than $10 \mathrm{~N}$, which is approximately $2 \%$ of the total value of the resistance force acting on the piston rod. This negligible dry friction was consequently neglected in further laboratory tests.

On the basis of data depicted in Fig. 3b, the shear stress $\tau$, fluid shear strain $\gamma$, plastic shear strain $\gamma^{I}$, may be written in a form

$$
\begin{aligned}
& \tau=\frac{F}{A} \quad \gamma=\frac{\Delta x}{h} \\
& \gamma^{I}=\gamma-\frac{\tau}{G} \\
& r=r_{1}+\frac{2}{3}\left(r_{2}-r_{1}\right) \quad A=2 \pi r l
\end{aligned}
$$


where $A$ is the shear surface area, $h$-gap height, $\Delta x$ - displacement increment, $G$ - Kirchhoff's modulus, $r_{1}$-internal radius of the gap, $r_{2}$ - outer gap radius, $r$-calculation radius, $l$ - length of the gap.

The scheme of the MR damper head, including the shape of the gap, is illustrated in Fig. 4.
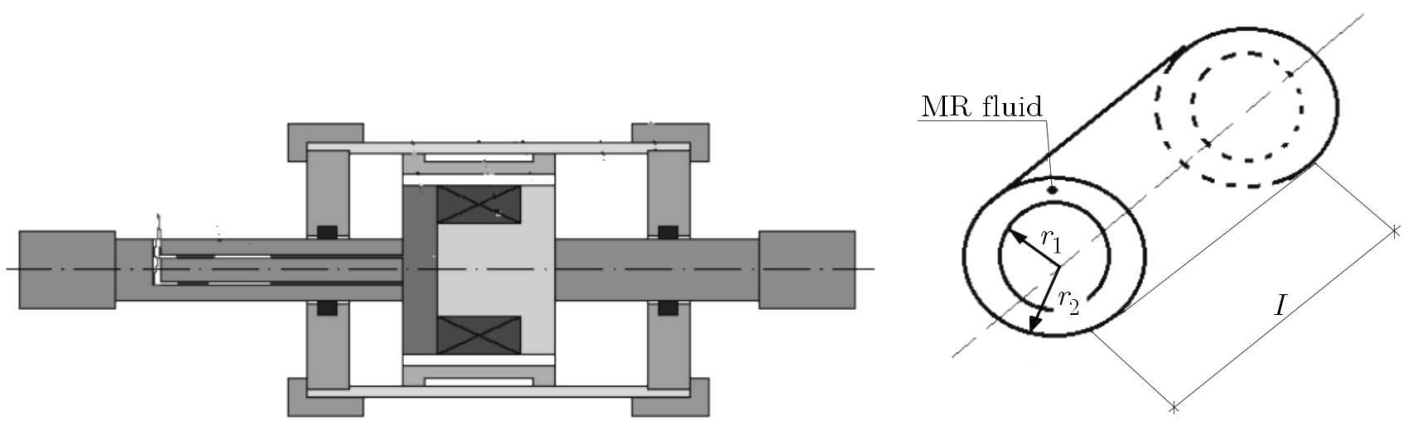

Fig. 4. Scheme of the damper with the selected working gap

To determine the shear rate value, it was necessary to prepare an additional shear strain-time characteristic. The shear strain in the loading was calculated from (4.1). As has been previously mentioned in the experimental part, the sine excitation rule has been taken into account. The authors made an assumption that the initial part of the applied in laboratory tests sine function (circled area in Fig. 5a) can be approximated using a linear function. Subsequently, the strain rate value of interest was determined by using the slope of the line to approximate the experimental data (Zalewski and Wolszakiewicz, 2011). The discussed stage of the identification process is depicted in Fig. 5b.
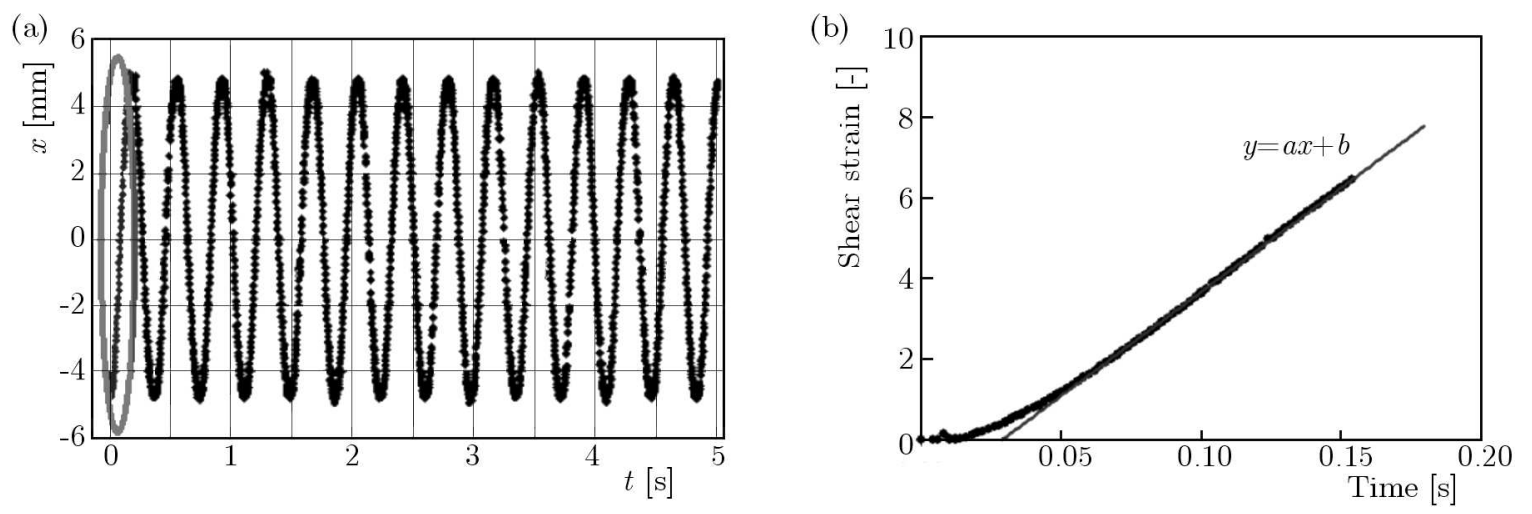

Fig. 5. (a) Sine excitation rule; (b) determination of the shear rate value

Shear rate values for all the experimentally applied excitation frequencies have been determined. For example, for the gap height $h=7 \cdot 10^{-4} \mathrm{~m}$, the calculated shear rate values for the oscillation frequencies $1.66,3.33,5.0 \mathrm{~Hz}$ were 73,144 and $2171 / \mathrm{s}$, respectively.

The next step of the identification process was determining the yield point values of the MR fluid (Pyrz and Zairi, 2007). This stage is graphically presented in Fig. 6.

The shear stress values were calculated from (4.1). It was assumed that the yield point value was defined as the intersection point of two lines, approximating the elastic and plastic parts of the shear stresses diagram (Fig. 6).

Another parameter which describes the MR fluid properties in the magnetic field is Kirchhoff's modulus, also called the shear modulus. Its values were determined according to the graphical scheme depicted in Fig. 6 (Pyrz and Zalewski, 2010). 


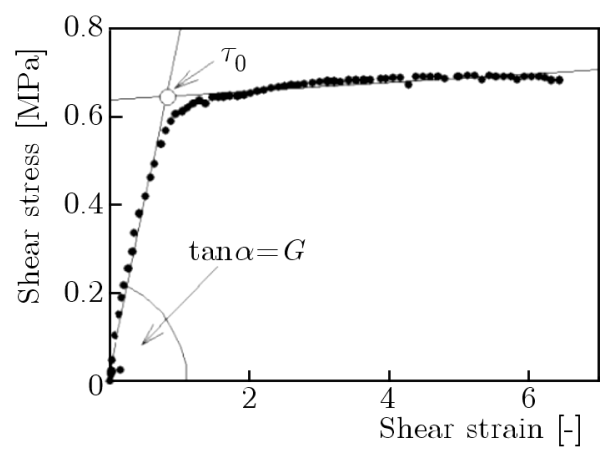

Fig. 6. Evaluation of the yield point $\tau_{0}$ and Kirchhoff's modulus $G$ of the MR fluid

Figure 7 illustrates the yield point variations obtained for three values of the current intensity $0.5,1.0,2.0 \mathrm{~A}$ and various shear rate values $73,144,2171 / \mathrm{s}$. Increasing the shear rate or current intensity results in increasing the yield point values.

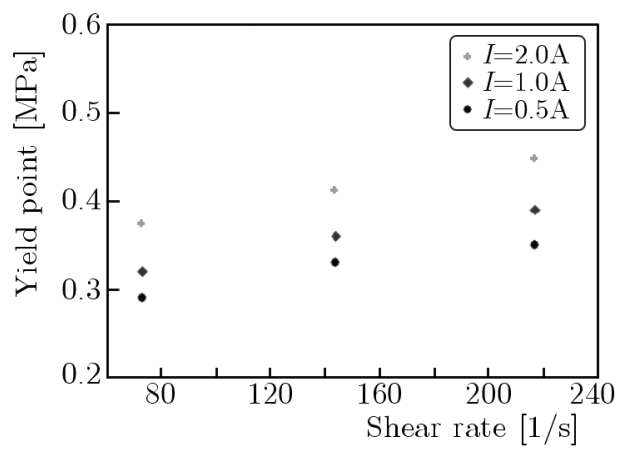

Fig. 7. Impact of the shear rate and current intensity on the yield point values; $h=0.0007 \mathrm{~m}$

In the next step of the identification strategy, a plot of the shear stress against the inelastic shear strain has been found (Fig. 8).

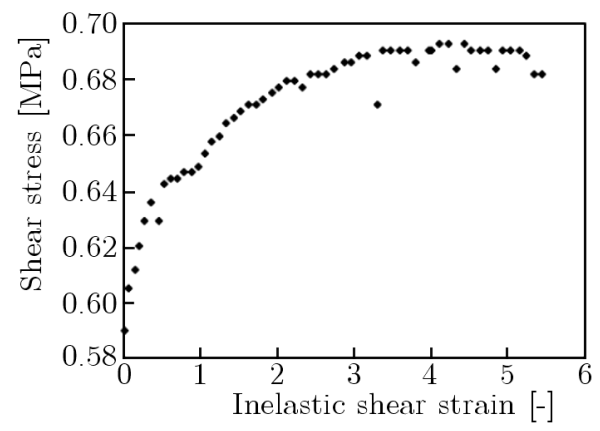

Fig. 8. Exemplary shear stress - inelastic shear strain diagram

\section{Bodner-Partom model}

The Bodner-Partom model is a typical law for metals. Equations of this model allow description of viscoplastic behavior of a material. This particular law has been selected from the wide list of potential viscoplastic formulations mainly due to its universality (Skalski, 2010). For example in Zalewski (2010) or Zalewski and Pyrz (2010), the authors used a similar formulation in the modeling process of an other innovative structure - Vacuum Packed Particles. The same model was also used for description of the non-linear properties of solid propellants (Zalewski 
et al., 2010), polymers (Zairi et al., 2007) or a metal alloy (Rowley and Thornton, 1996). The constitutive formulation of Bodner-Partom can be expressed in the following form (Bodner and Partom, 1975)

$$
\dot{\varepsilon}^{\prime i j}=\frac{3}{2} \dot{p} \frac{\sigma^{\prime i j}}{J\left(\sigma^{\prime r s}\right)}
$$

where $\dot{\varepsilon}^{\prime i j}$ is the deviatoric plastic strain rate tensor, $\dot{p}$ - accumulated inelastic strain rate, $\sigma^{\prime i j}$ - deviatoric stress tensor and $J\left(\sigma^{\prime r s}\right)$ - invariant of the plastic strain rate tensor.

After analysing the experimental results, the authors suggested some modifications to the original Bodner-Partom viscoplastic model for the description of the MR fluid behavior. These are related to omitting the hardening functions. The simplified constitutive law consists of three material parameters: $n, R_{0}, D_{0}$, dependent on four operational variables: plastic shear rate $\dot{\gamma}^{I}$, current intensity $i$, temperature $t$, and gap height $h$. The constitutive equation of the BodnerPartom law was finally written in the form (Skalski, 2010)

$$
\dot{\gamma}^{I}=2 D_{0} \exp \left[-\frac{1}{2}\left(\frac{R_{0}}{\sqrt{3} \tau}\right)^{2 n} \frac{n+1}{n}\right] \operatorname{sgn}(\tau)
$$

where $n, R_{0}, D_{0}$ are model parameters.

A large number of parameters describing the constitutive equations cause considerable problems with their identification. Identification methods of the Bodner-Partom model parameters are well described by Pyrz and Zairi (2007). In this paper, the methodology and the identification of parameters of the B-P law are based on the scheme given by Skalski (2010). The parameters estimation has been performed using the Marquardt-Levenberg algorithm.

The yield stress values obtained for different shear rates values allow determination of the first two parameters of the considered viscoplastic model $\left(n, R_{0}\right)$.

It can be assumed that for small values of inelastic deformation, the impact of the isotropic hardening is $R=R_{0}$, and the kinematic hardening in negligible. The following equation (5.3) can thus be treated as the Bonder-Partom contractual definition of the yield point and can be presented in the following form

$$
\tau_{0}=\frac{R_{0}}{\sqrt{3}}\left(\frac{2 n}{n+1} \ln \frac{2 D_{0}}{\dot{\gamma}^{I}}\right)^{-\frac{1}{2 n}}
$$

Figure 9 shows the initial yield point values $\tau_{0}$ corresponding to the three experimentally investigated shear rate values. Then, using the least squares method and condition (5.3), $n$ and $R_{0}$ parameters can be estimated based on the plot in Fig. 9. The parameter $D_{0}$ is arbitrarily chosen (Kłosowski et al., 2004).

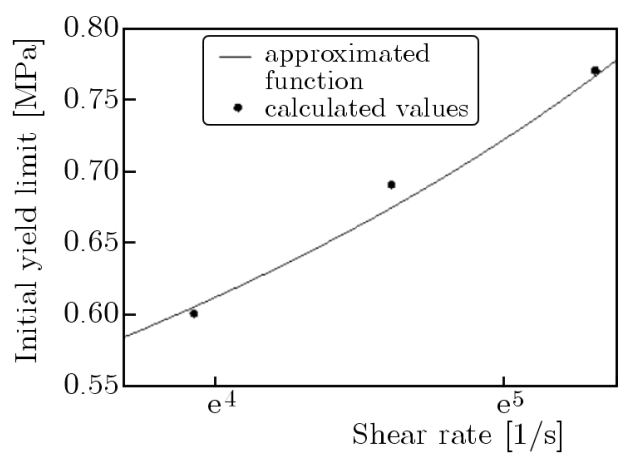

Fig. 9. Evaluation of $\mathrm{n}$ and $R_{0}$ parameters of the B-P model 
The final version of the B-P model for the investigated MR fluid can be written in the form

$$
\dot{\gamma}^{I}=2 D_{0} \exp \left[-\frac{1}{2}\left(\frac{R_{0}(t, i, h)}{\sqrt{3} \tau}\right)^{2 n(t, i)} \frac{n(t, i)+1}{n(t, i)}\right] \operatorname{sgn}(\tau)
$$

where

$$
n(t, i)=0.18+0.10 i-0.0001 t \quad R_{0}(t, i, h)=\frac{1}{h}(6.8-0.07 i-0.01 t)
$$

The value of the $D_{0}$ parameter was selected $10^{6} 1 / \mathrm{s}$ according to (Skalski, 2010).

\section{Numerical simulations and conclusions}

The identified viscoplastic model was used to carry out numerical simulations to verify the proposed mathematical model with experiments and to describe the behavior of the MR fluid in the working gap of the head according to the experimental data. Selected verification results are depicted in Fig. 10.
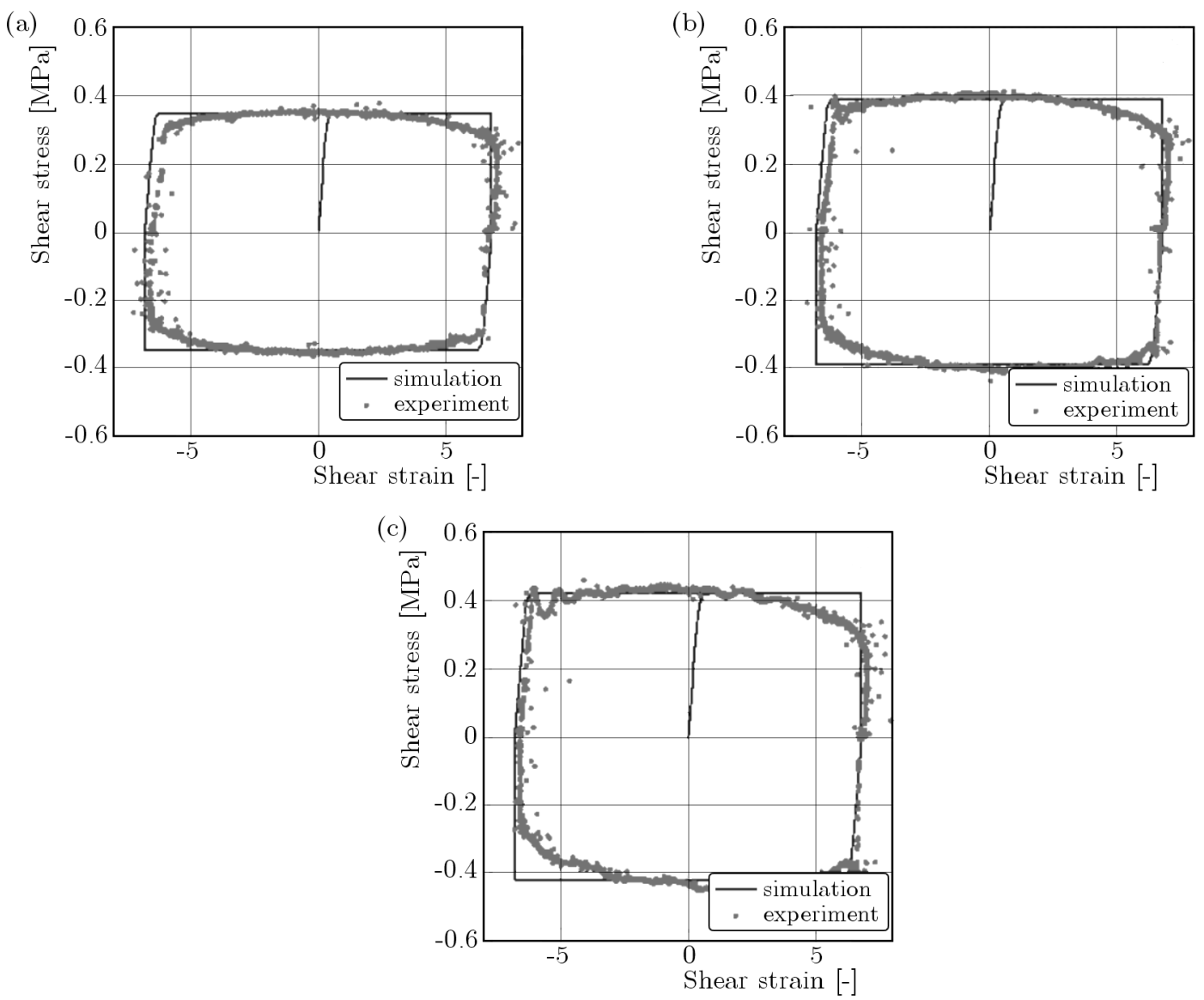

Fig. 10. Comparison of numerical simulation results of the Bodner-Partom model with experimental data; $I=1.0 \mathrm{~A}$ and shear rate: (a) $731 / \mathrm{s}$, (b) $1441 / \mathrm{s}$, (c) $2171 / \mathrm{s}$

In this paper, the viscoplastic behavior of a typical MR fluid has been studied. The inelastic part of the constitutive law is governed by a unified model using internal variables representing all aspects of viscoplastic deformation during the loading process of the MR damper. In order to acquire realistic material parameters form the experimental data, an analytical methodology has 
been applied. The initial results have been verified by numerical simulation of the laboratory tests using the identified material parameters. In all investigated cases, a relatively good coincidence of the experimental and numerical curves can be observed. This confirms the universality of the Bodner-Partom model and its capacity to capture the real behavior of an MR fluid.

A hybrid methodology, coupling both analytical and numerical identification (Zalewski and Pyrz, 2013) and incorporating knowledge of the specific problem is worth investigating in future studies.

\section{References}

1. Bajkowski J., Dudziak B., ZaLewski R., 2008, Experimental research of a magnetorheological damper with various crevieses - modeling and simulations, Machine Dynamics Problems, 32, 14-23

2. Bajkowski J., Jasiński M., Mączak J., Radkowski S., Zalewski R., 2012, The active magnetorheological support as an element of damping of vibrations transferred from the ground to large-scale structure supports, Key Engineering Materials, 518, 350-357

3. Bodner S.R., Partom Y., 1975, Constitutive equations for elastic-viscoplastic strain-hardening materials, Journal of Applied Mechanics, 42, 385-389

4. Carlson J.D., Goncalves F., 2008, Controllable fluids come of age, 11th International Conference on New Actuators/5th International Exhibition on Smart Actuators and Drive, Conference Proceedings Book Series: Actuator-International Conference and Exhibition on New Actuators and Drive Systems, 477-480

5. Carlson J.D., Weiss D., 1994, A growing attraction to magnetic fluids, Machine Design, 66, 61-66

6. Dyke S.J., Spencer B.F., Sain M.K., Carlson J.D., 1996, Modeling and control of magnetorheological dampers for seismic response reduction, Smart Materials and Structures, 5, 5, 565-575

7. Goncalves F.D., 2005, Characterizing the behavior of magnetorheological fluids at high velocities and high shear rates, $\mathrm{PhD}$ thesis, Virginia Polytechnic, Blacksburg

8. Holnicki-Szulc J., Graczykowski C., MikuŁowski G., Mróz A., PawŁowski P., 2009, Smart technologies for adaptive impact absorption, Solid State Phenomena, 154, 187-194

9. KŁosowski P., ZaGubień A., Woźnica K., 2004, Investigation on rheological properties of technical fabric Panama, Archive of Applied Mechanics, 73, 9/10, 661-681

10. Maślanka M., Sapiński B., Snamina J., 2007, Experimental study of vibration control of a cable with an attached MR damper, Journal of Theoretical and Applied Mechanics, 45, 4, 893-917

11. MikuŁowski G., Holnicki-Szulc J., 2007, Adaptive landing gear conceptfeedback control validation, Smart Materials and Structures, 16, 2146-2158

12. PyrZ M., ZAIRI F., 2007, Identification of viscoplastic parameters of phenomenological constitutive equations for polymers by deterministic and evolutionary approach, Modeling and Simulation in Materials Science and Engineering, 15, 85-103

13. Pyrz M, Zalewski R., 2010, Modeling of granular media submitted to internal underpressure, Mechanics Research Communications, 37, 2, 141-144

14. Rowley M.A., Thornton E.A., 1996, Constitutive modelling of the visco-plastic response hastelloy-X and aluminum alloy 8009, Journal of Engineering Materials and Technology, 118, 1, 9-27

15. SApiński B., Filuś J., 2003, Analysis of parametric models of MR linear damper, Journal of Theoretical and Applied Mechanics, 41, 215-240

16. Skalski P., 2010, Analysis of viscoplastic properties of a magnetorheological fluid in operational conditions of a damper's work, Ph.D. thesis, Warsaw University of Technology 
17. WU W., 2006, Theoretical and experimental study on cable vibration reduction with MR damper, Ph.D. thesis, Louisiana State University

18. Zairi F., Woznica K., Nait-Abdelaziz M., Gloaguen J.M., 2007, Elasto-viscoplastic constitutive equations for the description of glassy polymers behaviour at constant strain rate, Journal of Engineering Materials and Technology, 129, 1, 29-35

19. Zalewski R., 2010, Constitutive model for special granular structures, International Journal of Non-Linear Mechanics, 45, 3, 279-285

20. Zalewski R., Nachman J., Shillor M., Bajkowski J., 2014, Dynamic model for a magnetorheological damper, Applied Mathematical Modelling, 38, 2366-2376

21. Zalewski R., Pyrz M., 2010, Modeling and parameter identification of granular plastomer conglomerate submitted to internal underpressure, Engineering Structures, 32, 8, 2424-2431

22. ZAlewski R., Pyrz M., 2013, Experimental study and modeling of polymer granular structures submitted to internal underpressure, Mechanics of Materials, 57, 75-85

23. Zalewski R., Pyrz M., Wolszakiewicz T., 2010, Modeling of solid propellants viscoplastic behavior using evolutionary algorithms, Central European Journal of Energetic Materials, 7, 4, 289-300

24. Zalewski R., Wolszakiewicz T., 2011, Analysis of uniaxial tensile tests for homogeneous solid propellants under various loading conditions, Central European Journal of Energetic Materials, 8, 4, 223-231

Manuscript received April 14, 2014; accepted for print June 3, 2014 